\title{
Gabriel Marcel y el pensamiento dialógico
}

\author{
«El pensamiento dialógico o movimiento dialógico no es aún conocido \\ en nuestro país. Se trata de una serie de obras y de autores - no de \\ escuelas-, que, de forma desigual, han aportado temáticas subterráneas \\ coincidentes en un desenvolvimiento central. Tratan sobre algo nuclear de la \\ naturaleza humana. \\ Este movimiento ha nacido varias veces, en los últimos doscientos años, \\ sin que sus autores lo hayan tematizado convenientemente o hayan tenido \\ conciencia de quienes fueran sus antecesores. \\ Quien cala en el pensamiento dialógico, encuentra que es una cuestión \\ absolutamente importante. Si bien este movimiento no está suficientemente \\ articulado como para pasar al gran público en genẹral, y a los filósofos en \\ particular, se puede ya decir que el pensamiento dialogico es lo más intere- \\ sante y lo más profundo que existe hoy en filosofia» '.
}

Comenzaremos investigando la entidad y antecedentes del pensamiento dialógico.

El contenido de esta exposición se encuentra, de un modo larvado, en mi tesis de licenciatura, defendida el año 1974, bajo el título «El misterio ontológico en G. Marcel». No obstante, en esta ocasión, voy a enriquecer aquellos conocimientos con nuevas aportaciones.

Dada la novedad del tema, juzgué oportuno «abusar» de las citas con el fin de remitir al lector a los textos centrales.

Mi reflexión se remansa al analizar el papel de la filosofía alemana dentro del pensamiento dialógico. Este trato de preferencia parece justificado.

Los escasos estudiosos del tema, consideran que la cuestión arranca de Fichte, Jacobi, o a lo sumo, de Kant: «La Critica del juicio es una obra forzada por las anteriores divisiones. Soblo este intento toma el singular en su esencia, es una penumbra y una nebulosa. ...Como dice Jacobi, sin el presupuesto de la cosa en sí no se puede entrar en la metafísica y con la cosa en sí no se puede permanecer en ella... (con Fichte) el pensar es soblo una de las dimen-

1. O. MARKet, El pensamiento Dialógico. Conferencia pronunciada en el Congrego de Filosofia de Alcalá de Henares. Julio, 1979. 
siones del yo. Lo característico del yo es el soy, no sólo en el sentido de existir, sino también en el sentido del ser. La actividad es su mismo constitutivo. Hay que recuperar el ser en forma de sujeto" ${ }^{2}$.

Estoy de acuerdo con la opinión anterior, pero conviene hacer una precisión, al parecer, importante: Los presupuestos del pensamiento dialógico surgieron imperfectamente con Platón y Sócrates: «...Esto ya es concreto, pero, no obstante, aún es siempre algo abstracto. Es el Noús de Anaxágoras y, mejor aún, el de Sócrates; allí comienza una totalidad subjetiva» ${ }^{3}$.

Platón escribió en diálogos, y, junto a su maestro ejercitó incansablemente «el arte de preguntar y el arte de responder», médula de la relación dialógica, o de la «dialéctica del diálogo».

Defender una raíz griega en el movimiento dialógico parece arriesgado y conviene justificarlo, pero un estudio profundo de El Parménides (el diálogo más importante en opinión de Hegel), El sofista, El banquete, y de los Libros VI,VII,VIII de La República, parece darme la razón.

Apuntaremos algunas citas al respecto. En el prefacio de Le mystère de l'être, G. Marcel nos confiesa: «El autor quiere situar este libro bajo el signo de Sócrates y Platón, aunque no fuera más que para protestar de forma expresa contra las deplorables confusiones a que ha dado lugar el horrible vocablo «existencialismo». Se le ha preguntado a veces, no sin cierta ingenuidad, por qué «ismo» consentiría en sustituirlo. Es absolutamente claro que el pensamiento que aquí se expresa se orienta deliberadamente contra todos los «ismos». Pero, en fin, si es necesario resignarse a buscar un rótulo, el autor, por razones evidentes, a fin de cuentas adoptaría el de neosocrático o socratismo cristiano" ${ }^{4}$.

Aún otra referencia a G. Marcel, que nos parece complementaria de la anterior: «Las conferencias que componen este volumen (Le mystère de l'être) fueron pronunciadas en la Universidad de Aberdeen (Gifford Lectures) hace ya unos cuantos años (1949-1950). Es propósito del autor mantener este carácter hablado" (dialogado). Considera que de este modo se destaca mejor no sólamente el carácter de búsqueda que orienta la obra, sino también y más especialmente el hecho de dirigirse, no a una inteligencia abstracta y anónima, sino a seres individuales en los que trata de despertar cierta vía profunda de reflexión por una verdadera anamnesis en el sentido socrático de la palabra” ${ }^{5}$.

2. A. Natal y D. Natal, Crónica de Congresos (La filosofía en España, 1978). Estudio Agustiniano. Vol. XIII Fasc. II (1978), 384.

3. G.W.F. HeGel, Vorlesungen uber die Geschichte der Philosophie. Trad. castellana de E. Terron. Buenos Aires, 1971, 206

4. G. MARCEL, Le Mystère de l'Étre. trad. Castellana de M.E. Valentié, Buenos Aires, $1964,9$.

5. G. MARCEL, Le Mystère de l'Être. trad. Castellana de M.E. Valentié, Buenos Aires, 1964,9 . 
Las afirmaciones de G. Marcel parecen bastante claras. Alude a una cierta mayéutica, arte de buscar, dirigida a seres individuales, con el deseo de originar una reflexión profunda, capaz de desembocar en una intersubjetividad dialógica, dialogal. Pero, no sólo interesa el resultado, también interesa el método, el proceso, porque, en el fondo, ambas realidades son indisolubles; incluso, podríamos afirmar que se trata de dos manifestaciones interdependientes de una misma realidad.

Según una idea del profesor E. Lledó, expuesta al prologar un importantísimo libro de R. Valls Plana, «(el) ensayo de organizar la praxis humana, desde los entresijos de las ideas, tiene una larga historia que comienza, de hecho, en el Libro VII de La República de Platón» ${ }^{6}$.

Dejemos hablar a Platón mismo. En El banquete dialoga con belleza y nostalgia acerca de la condición humana. Igual que en otras importantes ocaciones, el «divino» deposita su mensaje en la caja fuerte de los mitos. Por boca de Aristófanes y en la atmósfera del amor, Platón nos habla de la condición humana: "La naturaleza humana en otro tiempo fue muy distinta de lo que es hoy. La humanidad se dividía en tres géneros, y no en dos sexos, como vemos. ...La diferencia entre estas tres clases de hombres pocedía de que el sexo masculino traía su origen del sol; el femenino, de la tierra, y el compuesto, de la luna. Porque la luna participa a la vez del sol y de la tierra» ?.

Estos andróginos eran fuertes y arrogantes por lo que trataron de luchar con los dioses. Platón dice que Homero se refiere a ellos cuando escribe de Efialtes y Otos. Intentaron escalar el cielo. Los dioses deliberaban perplejos no sabiendo qué hacer. Por fin Zeus dijo: «Creo tener el medio de dejar vivir a estos hombres haciéndolos cesar al mismo tiempo en su petulancia, debilitando sus fuerzas. Dividiré a cada uno en dos, y debilitados los individuos, duplicaré el número de servidores para nosotros. En adelante marcharé así sobre dos pies. ...Y diciendo esto, dividió a los hombres en dos, como los que cortan una serba para guardarla en sal. ...Cada uno de nosotros es, por consiguiente, la mitad de un hombre, como la mitad cortada de un todo, a semejanza de un lenguado; y de uno que fuera se hizo dos. Por eso busca cada uno su propia mitad (al otro)" ${ }^{8}$.

No creo que se pueda negar que estos textos son iniciadores del pensamiento dialógico...

Hace unos meses, comentando con otro profesor mis opiniones sobre G. Marcel, me decía: «Tú lo que quieres es sustituir el Yo de Kierkegaard por el de Fichte, o Schelling o Hegel, no sé».

6. LLeDO, Prólogo a «Del Yo al Nosotros (Lectura de la Fenomenología del espiritu de Hegel). Barcelona, 1971,7.

7. Plafón, El Banquete: Trad. castellana de R. Urbano. Madrid, 1923,66.

8. Platón, El Banquete. Trad. castellana de R. Urbano. Madrid, 1923,66. 
- «Pues, hombre, le contesté. Ya sabes que Kierkegaar fue discípulo de Schelling en Alemania, y le 'profesó una gran admiración'. Así que un alumno inteligente, teniendo un buen profesor, algo debio de aprender. Con todo, affadí, convendría analizar de nuevo los ingredientes que poseen algunas filosofias actuales, existenciales o marxistas, por ejemplo. No acierto a comprender a Marcel, Sartre, Heidegger o Marx, sin los presupuestos establecidos por Fichte, Schelling o Hegel. Algunos textos de Heidegger están inspirados, o mejor, casi transcritos de Hegel. Afirmar esto hace algunos años podía resultar escandaloso, pero 'los tiempos están cambiando'».

También es cierto que las interpretaciones de Hegel han variado. $Y$ al variar la concepción, varían concomitantemente algunas redes secundarias de relaciones que se intercomunicaban con ésta, como varían los satélites cuando el planeta se desplaza. «Esto significa que el mismo (o aproximadamente el mismo) conjunto de saber fáctico permite un gran número de interpretaciones racionales fundadas y, sin embargo, completamente distintas... Desde la posición del marxismo institucional, la cuestión es clara: en el ano 1945 el único juicio marxista verdadero sobre Hegel se encontraba en la afirmación de que fue un chauvinista alemán, un apologista de la guerra, un enemigo de los pueblos eslavos y un precursor del fascismo; en el ano 1954 se consideraba verdadero decir que fue un destacado idealista dialéctico, que desempeñó un gran papel en la creación de la filosofía de Marx" ${ }^{9}$.

R. Valls Plan, el mejor intérprete de Hegel hasta el presente, resulta tajante y clarificador: «El interés por la Fenomenología (del Espiritu) procede en gran parte del marxismo y del existencialismo. Los pensadores afiliados a estas corrientes se han visto obligados a dirigir su atencion hacia esta obra primeriza de Hegel, un tanto olvidada hasta nuestro siglo, porque ella constituye el suelo inmediato en el cual pudieron nacer las filosofias actuales. ...Pero sobre todo, por lo que se refiere al marxismo y existencialismo, si bien al principio en la persona de sus fundadores - Kierkegaard y Marx -, tuvieron un acento marcadamente polémico contra Hegel, resulta hoy históricamente claro que la Fenomenología abrió el espacio mental que los hizo posibles» ${ }^{10}$.

9. L. Kolakovski, Der Mensch ohne Alternative. Trad. castellana de A.P. Sánchez. Madrid, 1970,19.

10. R. Valls Plana, Del Yo al Nosotros (Lectura de la Fenomenología del espiritu de Hegel). Barcelona, 1971, 7.

Como dice S. Beauvoir, Pour une morale de l'ambigutté. Paris 1962, 23-24: «En affirmant que la source de toutes les valeurs réside dans la liberté de l'homme, l'existentialisme ne fait que reprendre la tradition de Kant, Fichte, Hegel qui selon le mot de Hegel lui-même, 'ont pris pour point de départ le principe selon lequel l'essence du droit et du devoir et l'essence du sujet pensant et voulant sont absolument indentiques'. Ce que définit tout humanisme, c'est que le monde moral n'est pas un monde donné, étranger à l'homme et auquel celui-ci devrait s'efforce d'accéder du dehors: c'est le monde voulu par l'homme en tant que sa volonté exprime sa réalité authentique». De muy sugerentes pueden calificarse las observaciones acerca de la relación entre Schelling, Kier- 
Los especialistas en idealismo alemán no tienen ya ningún reparo en deferder lo que los novatos investigadores pronunciábamos en voz baja hace diez años. Poco a poco se llega a la conclusión de que el idealismo no niega la realidad, ni la ha negado nunca, sino que es un estudio profundísimo de la subjetividad, que además está a la base de importantes corrientes actuales de pensamiento. Hermenéuticamente era una ficha clave. No decimos que fuera todo el rompecabezas conceptual, sino una pieza imprescindible: «El pensamiento dialógico podrá desembocar en una antropología ontológica, pero de ninguna manera podrá esquivar el idealismo alemán. La temática dialógica surgió en el idealismo y precisamente con Fichte»" ${ }^{11}$.

La cuestión dialógica, después de su balbuceo en Grecia, adquirió en el idealismo alemán una nueva perspectiva y fundamentación, en relación con la problemática de la libertad; los griegos, extremadamente clarividentes en algunos campos, sólo rozaron el tema de la persona, su libertad e intersubjetividad: «La diferencia total entre los pueblos orientales y los pueblos donde no domina el régimen de esclavitud es que éstos saben que son libres, que son libres por sí.

Los orientales son también en sí, pero no existen como libres. Esto constituye el enorme cambio de estado ocurrido en la historia universal, si el hombre es solamente en sí libre, o, si él sabe que es su noción, su determinación, su naturaleza existir como individuo libre. ...El hombre tiene a la libertad como su sustancia. ...El hombre es libre solamente si él sabe que lo es. ...Solamente este saber libera al hombre»" ${ }^{12,}$

Y más adelante Hegel puntualiza: «Se pueden comprender las filosofias de Platón y Aristóteles; pero ellas no contestan a nuestras preguntas; porque responden a otras necesidades. Por ejemplo, en Platón nosotros no encontramos contestadas ni la cuestión de la naturaleza de la libertad, ni la del origen del mal; y precisamente estas cuestiones nos preocupan a nosotros. ...La exigencia infinita de la subjetividad, de la independencia del espíritu en sí, aún era extraffa a los atenienses. El hombre aún no se había vuelto tanto hacia sí como en nuestra época. Indudablemente el hombre era sujeto, pero no se había puesto como tal». ${ }^{13}$.

Sabido es que Hegel es un filosofo de la libertad, y por lo mismo de la

kegaard y Marcel, entre otros, expuesta por W. KASPER, «Crisis y nuevo planteamiento de la cristologia en el pensamiento de Schelling», W. KASPER, H. KUNG, Teología de la Cruz. Salamanca, 1979, 193,196-197.

11. O. MARKET, El pensamiento Dialógico. Conferencia pronunciada en el Congrego de Filosofia de Alcalá de Henares. Julio, 1979.

12. G.W.F. HEGEL, Vorlesungen uber die Geschichte der Philosophie. Trad. castellana de E. Terrón. Buenos Aires, 1971, 57.

13. G.W.F. HEOEL, Vorlesungen uber die Geschichte der Philosophie. Trad. castellana de E. Terrón. Buenos Aires, 1971,99. 
subjetividad. Esta denominación no cuadraría para Sartre, a no ser en cuanto imita a Hegel. El autor de La Fenomenología del Espíritu, investiga en qué momentos concretos de la Historia el espíritu se libera, y esta liberación no sería posible si faltasen esos momentos: «Es usual simplificar las etapas históricas de la libertad, en Hegel, reduciéndolas a tres:

a) En el mundo oriental sólo un hombre es libre, el Jefe, es decir, el déspota.

b) En el mundo clásico, griegos y romanos, sólo algunos son libres: los ciudadanos. Hay esclavitud.

c) Sólo en las naciones germanas, con el cristianismo, se llega a la conciencia de que todo hombre, en cuanto hombre, es libre.

...Del déspota nos dice: esa libertad es sólo capricho, barbarie, y hosquedad de pasión. Es decir, no era libertad. Respecto a los griegos, ciertamente Hegel dice que en ellos surgió la conciencia de la libertad. Pero anota rápidamente: «...ni ellos ni los romanos supieron que el hombre, en cuanto tal, era libre. No lo supieron ni Platón, ni Aristóteles»" ${ }^{14}$.

Fichte iniciaría por segunda vez y decididamente la temática dialógica — dialéctica de la libertad-. Más de setenta páginas dedica en un importante libro de juventud ${ }^{15}$.

Entre las múltiples obras de Fichte sugestivas dialógicamente, habría que mencionar una traducida al castellano, de la que extractaremos algunos textos. Sesenta páginas, que constituyen la tercera parte de este volumen ${ }^{16}$, están escritas en forma de diálogo, desarrollando una densa conversación entre «el yo y el espíritu».

Fichte, al parecer, establece un «cambio de marcha en filosofía», fundamenta el pensamiento dialógico, una nueva forma de ser o de interpretar la realidad de la relación: «Creo conocer, nos dice, parte del mundo que nos rodea... pero, ¿qué soy yo y cuál es mi destino?» ${ }^{17}$.

He aquí la pregunta fundamental para Fichte, retomada, sin duda, si bien con una nueva orientación, de su admirado E. Kant. Recordemos que las obras más importantes de Kant podrían ser las respuestas a estas preguntas: ¿Qué puedo saber?, ¿qué puedo hacer?, ¿qué me es lícito esperar?, y en definitiva, ¿qué es el hombre?

14. R. FlóREZ, La Historia como realización de la libertad en Hegel. Madrid, 1973, 31-32.

15. J.G. FICHTE, Grundlege des Naturrechts nach den Prinzipien der Wissemschaftslehre. Jena und Leipzig, 1796-97 (2 vols.). No existe traducción castellana, pero sí francesa.

16. J'G. FichTE, Ueber die Bestimmung des-Menschen. Trad. Castellana de E. Ovejero y Maury. Madrid, 1976.

17. J.G. FichTE, Ueber die Bestimmung des Menschen. Trad. Castellana de E. Ovejero y Maury. Madrid, 1976, 11. 
Si es cierto que algunos temas fichteanos arrancan de Kant, no es menos cierto que no se quedan en el autor de la Crítica de la razón pura. Fichte hubiera "aprendido a nadar tirándose primero al agua» da prioridad a la razón práctica sobre la razón pura: «Aun aquel mismo que no hubiera pensado jamás en su destino moral, si pudiera existir algún ser de esta naturaleza. ...Si no llegase a conocer este mundo por el pensamiento de sus deberes, llegaría a conocerlo seguramente por las exigencias de su derecho. Lo que él tal vez no se exigiera a sí mismo, lo exigiría seguramente a sus semejantes para con él, a saber: que le tratasen con respeto y consideración, no como a una cosa irracional, sino como un ser libre y autónomo; y antes se vería obligado él también, para que le tratasen de este modo, a prestar esta misma consideración y respeto, y a tratar a los demás como seres libres e independientes» ${ }^{18}$.

Una vez más insistiendo sobre la primacía de la razón práctica: «Nosotros no obramos porque conozcamos, sino que conocemos porque estamos destinados a la acción; la razón práctica es la raíz de toda razón» ${ }^{19}$.

El mundo de las personas y sus relaciones ocupa una región bien específica dentro de la ontología; se trata de una cuestión diferente que requiere un tratamiento ético, estético y gnoseológico, diferente.

Lo que pretende el autor de El destino del hombre es una ontificación o una ontologización del mundo personal e interpersonal, y aquí reside el "Grund» del movimiento dialógico. La ética y la estética son relativas a una sola especie animal que situó la belleza y la libertad altas en su axiología. Se trata de unos animales que existen pastoreando los otros entes. Fichte se explica así: «...El conocimiento que los seres inteligentes tienen unos de otros en el mundo sensible es un hecho inexplicable por las leyes de la naturaleza y del pensamiento. Lo mismo sucede con su acción recíproca. No podemos darnos cuenta del uno y del otro de estos dos hechos, sino recurriendo a la hipótesis de una inteligencia o una voluntad infinitas, en el seno de la cual dichos seres inteligentes entran en relación los unos con los otros» ${ }^{20}$.

Es bien probable que M. Buber, y el mismo Marcel suscribiesen parte de este texto fichteano.

F.H. Jacobi llegó a la conclusión, antes que Fichte, de que la entidad fundamental del ser humano venía dada en sus relacianes con los otros. Novalis, discípulo de Fichte, compartió esta misma teoría.

18. J.G. FichTE, Ueber die Bestimmung des Menschen. Trad. Castellana de E. Ovejero y Maury. Madrid, 1976, 115-116.

19. J.G. FICHTE, Ueber die Bestimmung des Menschen. Trad. Castellana de E. Ovejero y Maury. Madrid, 1967, 117.

20. J.G. FICHTE, Ueber die Bestimmung des Menschen. Trad. Castellana de E. Ovejero y Maury. Madrid, 1967, 154. 
La influencia del idealismo alemán en los filósofos existenciales, es de hecho, irrefutable. Sin embargo, conviene hacer una aclaracion: Si bien la influencia es indudable, en algunos casos, podría ser indirecta, como, me sugiere P. Ricoeur. Concretamente, en el caso de G. Marcel, si bien hay que admitir un influjo directo, tampoco se puede olvidar que el idealismo alemán le deslumbró a partir de su implantación en Inglaterra - Coleridge, Bradley-, y Estados Unidos - Royce-.

Algunas veces se ha afirmado que G. Marcel no conocía a Fichte y que, en consecuencia, la deuda de Marcel con Fichte era un supuesto producto de la imaginación; pero el «filósofo itinerante» cita a Fichte, por ejemplo, cuando habla de la posibilidad del arte dramático: «Yo censuraba entonces (quizás equivocadamente), yo censuraba entonces a la doctrina de Fichte el que se desinteresase de lo que más tarde había de denominarse la facticidad que me constituye en individuo particular. ...En este sentido, quedaba fundada para mí la posibilidad del arte dramático. ...De este modo, sin que en aquella época lo comprendiera de una manera distinta, se hallaba realizada la articulación central entre mi principal investigación filosófica y mi creación en el orden dramático»» ${ }^{21}$.

Como se ve, G. Marcel conocía a Fichte, incluso con anécdotas biográficas: «On peut évoquer aussi Madame Staël demandant à Fichte de lui dire en deux mots en quoi consistait sa philosophie» ${ }^{22}$.

Pero escuchemos la confesión marceliana en el Discurso Autobiográfico: «En el ámbito filosófico estaba yo profundamente influido por los pensadores germanos. Sobre todo me impresionaban profundamente los herederos espirituales de Kant. Y así, cuando llegó el momento de escribir mi tesis para el diploma de la enseñanza superior, dediqué el trabajo a estudiar el influjo de Schelling en el mundo conceptual de Samuel Taylor Coleridge» ${ }^{23}$.

Este texto descalificaría a quienes se escandalizan al oír que G. Marcel hundió sus raíces en el idealismo alemán.

Sería conveniente clarificar si Fichte fue «heredero espiritual de Kant». Refiramos, al respecto, un dato biográfico recogido en algunas Historias de la Filosofía: J.G. Fichte nació en 1762. Inesperadamente se hizo famoso por un escrito de juventud ${ }^{24}$, ya que, al publicarse, por casualidad, anónimo, pasó durante tiempo por ser una obra de Kant largamente esperada. Tanto se había identificado Fichte con el pensamiento de Kant.

21. G. MARCEL, Auf der Suche nach Wahrheit und Gerechtigkeit. Trad. castellana de de J. Godo. Barcelona, 1967, 13.

22. G. MÁRCEL, Testament philophique. Revue de Métaphysique et de morale, $\mathrm{N}^{\circ}{ }^{3}$, (1969), 254.

23. G. MARCEL, Der Philosoph und der Friede. Trad. castellana de Ed. Herder. Barcelona, 1967,8 .

24. J. G. FICHTE, Kritik aller Offenbarung, 1927. 
Qué decir de la influencia de Schelling en Marcel. En principio, parece razonable admitir que si una persona se dedica a hacer una tesis sobre el pensamiento de otra o sobre el influjo de este pensamiento, será porque realmente le interesa o simpatiza con él. Convendría, pues, clarificar la deuda marceliana con Schelling y Coleridge.

Sabemos que Schelling, Hölderlin, Hegel son amigos y estudian juntos en el Seminario de Tubinga. «En 1801, Hegel inició su carrera académica en Jena, para entonces el centro filosófico de Alemania. Fichte había enseñado allí hasta 1799, y en 1798 Schelling había sido nombrado profesor. La filosofia social y jurídica de Kant, su Metaphysik der Sitten, había sido publicada en 1799, y la revolución que había creado en filosofia con sus tres Críticas aún ejercía una importante influencia en la vida intelectual» ${ }^{25}$.

Schelling es la articulación entre idealismo y romanticismo. Es la vertiente estética del pensamiento dialógico.

En efecto, Goethe fue quien recomendó a Schelling para que fuese nombrado catedrático en Jena. Allí, Schelling se casa con Carolina Schlegel, del Círculo romántico. Posteriormente Schelling fue secretario y presidente de la Academia de Bellas Artes. Schelling ejerció un tremendo hechizo sobre poetas, artistas e intelectuales de su tiempo. "A Hegel llegó a conocérsele incluso como un mero discípulo de Schelling... Hegel va progresivamente tomando distancia frente a su antiguo condiscípulo, Schelling, quien, aunque cinco años más joven que él, le había precedido en celebridad»" ${ }^{26}$.

Tanto las influencias de Schelling en Inglaterra, como las de Hegel en Estados Unidos, son estudiadas por G. Marcel: «Si tratásemos deliberadamente de reconstruir influencias formativas, hariamos mejor en citar filosofos que ocuparon su atención en una edad más temprana: Schelling, que fue el tema de su tesis de Licenciatura, en la que compara las ideas metafísicas de Schelling con las de Coleridge. O Josiah Royce (neohegeliano) sobre el que Marcel hizo en 1917 un estudio que sigue siendo clásico hoy día ${ }^{27}$.

Para calcular el gran impacto del idealismo en Inglaterra - por los años en que Marcel escribía su tesis - citaré un texto de I.M. Bochenski: «Para comprender mejor a Moore es necesario que sepamos que Inglaterra estaba casi completamente dominada por los hegelianos hasta finales de 1925 . Un amigo mío, muerto recientemente, me dijo que quien no siguiese a Bradley no era hombre para conversar, nadie quería disputar con él. O se era seguidor de

25. H. MARCUSE, Reason and Revolution. Hegel and the Rise of Social Theory. Trad. castellana de J. Fombona. Madrid, $1974^{4}, 48$.

26. V. GOMEZ PIN, Conocer a Hegel y su obra. Barcelona, 1978, 19.

27. K.T. Gallagher, The Philosophy of G. Marcel. Trad. castellana de A. Gutièrrez, Madrid, 1968, 10. 
Bradley o no se era filósofo. Utro pensador me contaba que cuando Bradley entraba (en la sala) pensaban que era una idea platónica» ${ }^{28}$.

Schelling y Hegel enseñaion juntos y conjuntamente publicaron el Kritischer Journal für Philosophie. Parece que hay que hablar de deudas intelectuales mutuas entre los dos idealistas, si bien La fenomenología del espíritu separa definitivamente a Hegel - el grande- de su compañero: «Tanto Glockner como Müller han advertido que a Hegel le sucedió algo extraño. Pues el primero dice, pese a su propia y no oculta admiración por Fichte: «Fichte lo sacó del curso que seguía: sin su precedente, Hegel no hubiese elaborado método dialéctico alguno: lo más probable es que hubiese ampliado el kantismo en forma análoga a la de Schiller»; y Müller escribe: «En Jena, su amigo Schelling era el mal espíritu y el seductor de Hegel. ...Hegel sucumbió al jolgorio e intentó hacer algo que no podía: «especular» e «interpretar» con igual frivolidad. Una vez que la fama de Schelling como flautista variopinto lo había hecho atrapar una invitación para ir a Würzburg ... volvió Hegel a su yo genuino... y el prólogo a la Fenomenología estampó una confesión pública» ${ }^{29}$.

Hegel marca una época. Divide las opiniones entre entusiastas seguidores y acérrimos detractores. Estos últimos, en algunos casos, utilizan los mismo presupuestos que critican. El reto de Hegel fue y sigue siendo -incluso en España - un revulsivo o una alternativa importante, casi omnipresente: «En efecto, Unamuno, a los dieciacho años, estudiante en Madrid, ....aprendió alemán traduciendo la Lógica de Hegel... En Unamuno hay una línea nuclear, una línea hegeliana... Nos encontramos, ya sin ninguna trasformación, la huella de Hegel en multitud de obras de Unamuno, sobre todo con la repercusión del tema hegeliano del «amo y del esclavo» ${ }^{30}$.

Éste es sólo un ejemplo que aún no permite hablar de la «casi omnipresencia». Sería conveniente estudiar a Pi y Margall, Castelar, Salmerón, etc., etc., pero nos vamos a contentar con mencionar, a título indicativo, la opinión de Víctor Gómez Pin, quien, en el congreso de Filósofos jóvenes - Sevilla, 1979- defendía la posibilidad de una interpretación metafísica de Freud, a partir de la Ciencia de la Lógica de Hegel.

Desde mi punto de vista, la mina más importante del pensamiento dialógico habría que descubrirla en las obras de Hegel, y concretamente en la Ciencia de la Lógica y Fenomenología del Espíritu. «...Estas experiencias sociales ocurrirán dentro de un espacio limitado por dos experiencias decisivas: prime-

28. I.M. Bochenski, Filosofía Analítica. Conferencia pronunciada en el Congreso de Filosofía de Alcalá de Henares. Julio de 1979. Trad. castellana de A. Natal. En vías de publicación.

29. W. Kaufmann, Hegel. Trad. castellana de V. Sánchez de Zavala. Madrid, 1979, 113.

30. M. PIZÁN, Los hegelianos en España y otras notas críticas. Madrid, 1973, 29-30. 
ramente, la experiencia inaugural de la intersubjetividad, dialéctica del señor y del siervo. ...En segundo lugar, la experiencia terminal de la Fenomenología que será una experiencia perfectamente horizontal e'igualitaria»" ${ }^{31}$.

Tanto Kierkegaard como Marcel acusan «agónicamente» el reto hegeliano: «Este diario - Diario Metafísico - comprende dos partes bien distintas: la primera fue redactada durante los meses anteriores a la guerra; aunque toda ella está orientada contra la dialéctica o, más exactamente contra toda doctrina que pretenda dar cuenta de la realidad mediante procedimientos dialécticos, ella misma está marcada por la impronta de las doctrinas que se propone combatir" ${ }^{32}$.

Una cuestión similar sugiere $P$. Ricoeur en el esclarecedor volumen, en el que profesor y alumno propician una larga reflexión dialogal sobre la obra de G. Marcel, a través de entrevistas:

-Paul Ricoeur.- Vous lisiez Schelling...

-G. Marcel.- Effectivement, je lisais Schelling et un peu Hegel; et puis j'ai lu surtout, et plus profondément, les penseur anglais néohégéliens et particulièrement Bradley" ${ }^{33}$.

Así pues, Marcel leyó un poco a Hegel y un mucho a los neohegelianos. Mas conviene reflexionar sobre ese «un peu Hegel». Me parece que G. Marcel quiere suavizar un poco el reto hegeliano. A una pregunta sobre Schelling, Marcel habla de Hegel... Por otra parte, si Marcel construye un sistema «face à Hegel», si lo cita repetidamente, resulta desconcertante «un peu Hegel».

Vamos a hacer una cuantificación. Tomemos las 45 primeras páginas del Journal Métaphysique. En la página 11, encontramos dos alusiones nominales a Hegel, intentando aclarar su postura respecto a las opiniones del filósofo idealista: "Quisiera luego definir mi actitud con respecto a Hegel en lo que atañe a la historia de la filosofía. La paradoja hegeliana consiste en la idea de que los sistemas ilustran la dialéctica aun antes de engendrarla - pues como el espíritu no es sino a condición que se haga, el für sich seyn supone el an sich seyn; es decir que los momentos de la dialéctica tienen que comenzar poniéndose como absolutos...» ${ }^{34}$.

En la página 20, tenemos otra cita sobre el concepto hegeliano de «progreso». En la página 21, una nueva alusión a «la demostración hegeliana de la relatividad del punto de vista del «sollen». En esta misma página, otra

31. R. Valls Plana, Del Yo al Nosotros (Lectura de la Fenomenología del espíritu de Hegel). Barcelona, 1971, 28. $1957,7$.

32. G. MARCEL, Journal Métaphysique. trad. Castellana de J. Rovira. Buenos Aires,

33. P. Ricoeur-G. MARCel, Entretiens. Paris, 1968, 16. 11.

34. G. MARCEL, Journal Métaphysique. trad. Castellana de J. Rovira. Buenos Aires, 1957, 
referencia a los neohegelianos. En la página 30, al hablar de conciencia y participación, añade Marcel: «Para decirlo como Hegel». En la página 45, nueva referencia a la «dialéctica de Hegel».

Comentamos solamente las alusiones directas, ya que hay varias alusiones indirectas a Hegel y a su obra, dentro de estas 45 páginas. También es cierto que no todas las obras de Marcel están igualmente nutridas de alusiones a Hegel, pero quien lea detenidamente la obra marceliana notará esta insistencia hegeliana.

Preocupado por estas y por otras cuestiones, decidí consultar a Paul Ricoeur. Mi carta iba dirigida en los siguientes términos: «Monsier, ...Après avoir lu votre livre «Entretiens Paul Ricoeur -Gabriel Marcel, et en connaissant la préference du «maître» envers vous, je voudrais vous poser quelques questions au sujet de la philosophie de Gabriel Marcel à qui je suis en train d'étudier despuis six annés.

$\left.1 .^{\circ}\right)$ J'ai pensé intituler ma thèse: «La participation chez Gabriel Marcel». Pensez-vous, Monsieur, que la «participation» est un bon accés à la pensée de Gabriel Marcel? Il paraît que la participation et la corporéité doivent être fondamentales dans une étude sur cet auteur.

$2^{\circ}$ ) Je pense que la philosophie allemande ha determiné dans une bonne partie l'oeuvre de Marcel - «je crois que ceci tient au fait que toute ma formation avait été idéaliste...». Croyez-vous que Marcel utilisse, peut-être, sans se rendre compte - 'je me plaçait tout a fait en marge de l'idéalisme traditionel» et «face à Hegel» - la méthode dialectique que Hegel utilisa, ou du moins, quelques- unes de ses presuppositions?...».

Con fecha 30 de marzo de 1977, Paul Ricoeur me responde lo siguiente: «Monsieur,

Je vous remercie au sujet de votre letre concernant votre projet de thèse sur «Gabriel Marcel». Je réponds à vos questions:

1) La question de la participation chez Gabriel Marcel est certainement un excellent accés à sa pensée...

2) Je ne crois pas que la philosophie allemane ait directement influencé Gabriel Marcel, sinon à travers les hegeliens anglais avec lesquels il était très familier. C'est porquoi je doute qu'on puisse trouver chez lui un équivalent de la méthode dialectique, du moins au sens de Hegel. Sa dialectique, s'il en est une, est non conclusive. Ce qu'il apelle «réflexion seconde» est d'un autre ordre. Mais on peut appeler dialectique les oppositions irréductibles à des indentités. Mais alors ne s'agit plus d'une philosophie de la médiation. La dialectique serait ici pluz près de celle de Kierkegaard que de celle de Hegel» ${ }^{35}$.

P. Ricoeur respondió clara y amablemente, mas sin detenerse a comentar

35. P. Ricoeur, Carta dirigida a A. Natal. Marzo, 1977. 
las problemáticas afirmaciones de $\mathrm{G}$. Marcel, que matizan las cosas, según mi parecer, en otra dirección. Debo reconocer que, si bien en algunas cuestiones mi opinión y la de P. Ricoeur son coincidentes, en la segunda discrepa de mi tesis. Sin embargo, Ricoeur conoce perfectamente la problemática. Entiendo que no desea abordarla en detalle por no dar pie a que alguien se atreva a llamar a Marcel idealista.

Por otra parte, dadas las deficiencias del lenguaje ordinario, resulta complejo precisar el sentido de dialéctica. Lo que yo afirmo y creo tener argumentos para hacerlo es lo siguiente: Hegel sustituyó el concepto de causalidad por el de relación, empleando perfectivamente el método dialéctico. Gabriel Marcel afirma que la relación entre personas es un constitutivo fundamental de éstas, y que dicha relación puede clarificarse o comprenderse en el pensamiento dialógico - dialéctico-. Indudablemente que esta dialéctica posee una orientación específica, pero utiliza los presupuestos de toda dialéctica (Heráclito-Platón-Hegel).

Intentaremos fundamentar las afirmaciones anteriores: «En la relación, el cuanto yo no tiene una determinación sólo indiferente, sino que se halla determinado cualitativamente, como referido puramente a su más allá; éste es ante todo un otro cuanto en general. Pero esencialmente éstos no se refieren uno a otro como cuantos extrínsecos, sino que cada uno tiene su determinación en esta referencia al otro. De este modo en este ser-en-otro suyo han vuelto dentro de sí; lo que cada uno es, lo es en el otro; el otro constituye la determinación de cada uno. El salir más allá de sí, (propio) del cuanto, tiene pues, ahora este sentido, que éste no se cambió ni solamente en su otro, ni en su abstracto, o sea en su negativo más allá, sino que ha alcanzado en éste su determinación; se encuentra a sí mismo en su más allá, que es otro cuanto» ${ }^{36}$.

En este texto subsisten importantes presupuestos del pensamiento dialógico. Evidentemente se trata de una dirección de pensamiento, de un sentido profundo con capacidad de superar (Aufhebung) las relaciones negativas y alienantes. Se trata de una relación enriquecedora, por la que, mediante los otros, nos descubrimos a nosotros mismos, como si los otros «tuvieran el secreto de lo que somos», el reconocimiento por el que nos identificamos con nosotros mismos.

Si Platón quiso sintetizar su doctrina en el «mito de la caverna», Hegel deseó condensar la suya a través de la «dialéctica del amo y del esclavo». Se trata de una profunda parábola que nos intenta mostrar los ingredientes o condiciones de posibilidad de una relación dialógica: «...El señor se relaciona con estos dos momentos: con una cosa como tal, objeto de las apetencias, y con la conciencia para la que la coseidad es lo esencial; y en cuanto que él, el

36. G.W.F. Hegel, Wissenschaft der Logik. Trad. Castellana de Augusta y R. Mondolfo. 2. vols. Buenos Aires, 1968, 275. 
señor, a) como concepto de la autoconciencia, es relación imediata de ser para sí, pero, al mismo tiempo, b) como mediación o como un ser para sí que sólo es para sí por medio de otro, se relaciona a) de un modo inmediato con ambos momentos y b) de un modo mediato, a cada uno de ellos por medio del otro" ${ }^{37}$.

En este caso, la relación establecida por el señor y el esclavo no es aún dialógica, porque no existe reconocimiento mutuo, no hay verdadera intersubjetividad, se realiza en el terreno del tener (avoir marceliano). El señor tiene bienes, tiene al esclavo para utilizarlo a su antojo, sin reconocerlo como persona. Hay que hablar de una relación objetal, problemática - en el sentido marceliano-, no dialógica, ni misteriosa. (Marcel da a estos términos un sentido propio que precisaremos más adelante).

Hasta este momento, "se ha producido, por tanto, un reconocimiento unilateral y desigual» ${ }^{38}$. Sin embargo, el camino hacia el saber absoluto sólo se puede lograr mediante un reconocimiento mutuo; "pero lo que hace la originalidad de la introducción hegeliana al saber absoluto es que el individuo no accede a este saber de manera solitaria e individualista. Su camino es a la vez dialéctico y dialogal. Entra en relación necesaria con otros individuos y alcanza el saber absoluto en comunidad. ...Para encontrar un antecedente histórico de semejante riqueza deberíamos remontarnos a la iniciación socráticoplatónica de la sabiduría» ${ }^{39}$.

La dialéctica del señor y el esclavo es, en su comienzo, un modelo de relación antidialógica, llevada a cabo por una conciencia desgraciada; pero la Fenomenología del espíritu que va del yo al nosotros, termina en la superación de este estado por medio de una intersubjetividad dialógica. También la intersubjetividad es el camino que recorre la Fenomenología del espíritu. "La buena conciencia no ha abandonado el puro deber o el en sí abstracto, sino que es el momento esencial que consiste en comportarse hacia los otros como universalidad. Es el elemento común de la autoconciencia, y ésta la sustancia en que el acto tiene subsistencia y realidad; el momento del ser reconocido por los otros» ${ }^{40}$.

R. Valls Plana lo resume así: «...Su primera realización es el reconocimiento desigual (señor-siervo) y su realización plena es el reconocimiento perfecto que instau ${ }^{a}$ la comunidad absoluta sobre la tierra»" ${ }^{41}$.

37. G.W.F. Hegel, Phanomenologie des Geistes. Trad. castellana del Instituto Cubano del Libro. La Habana, 1972, 117.

38. G.W.F. Hegel, Phanomenologie des Geistes. Trad. castellana del Instituto Cubano del Libro. La Habana, 1972, 118.

39. R. Valls Plana, Del Yo al Nosotros (Lectura de la Fenomenología del esptritu de Hegel). Barcelona, 1971, 22.

40. G.W.F. HeGel, Phanomenologie des Geistes. Trad. castellana del Instituto Cubano del Libro. La Habana, 1972, 373.

41. R. Valls Plana, Del Yo al Nosotros (Lectura de la Fenomenología del Espíritu de Hegel). Barcelona, 1971, 373. 
El movimiento dialógico - fundamentalmente alemán y francés- resurge con una fuerza especial a partir de 1919. En 1919 aparece Individuo y Comunidad de T. Litt; el neokantiano $\mathrm{H}$. Cohen, en el mismo año, publica $L a$ religión de la razón a partir de la obra del judaismo». En $1921 \mathrm{~F}$. Rosenzweig escribe La estrella de la salvación. También en 1921, brilla uno de los grandes del pensamiento dialógico F. Ebner ${ }^{42}$, que atribuyó a Feuerbach un cierto protagonismo en el movimiento dialógico, y que llegó a la conclusión de que: el hombre se angustia solo, solamente puede realizarse mediante una actitud creativa'en las relaciones con los otros.

Desde estas fechas, el movimiento dialógico se ve enriquecido por varias aportaciones: M. Buber, K, Löwith ${ }^{43}$, E. Husserl -sus Reflexiones sobre Fichte permanecen inéditas-, M. Heidegger, M. Merleau-Ponty, P. Laín Entralgo ${ }^{44}$, G. Marcel en quien nos vamos a detener:

La valiosa aportación de G. Marcel consiste, a mi juicio, en haber reconocido a las relaciones humanas creadoras, intersubjetivas o dialógicas, la categoría de dialógico-ontológicas, de haber situado a estas relaciones en la región ontológica que les correspondía. Es decir: siguiendo, de alguna manera, la dirección hegeliana - expresada hace algunas líneas-, comenzó la construcción de una antropología ontológica, basada en las relaciones humanas, de forma análoga a como el marxismo y la sociología se basan en las relaciones de producción, pero entendidas en un sentido especial, dialógico. Se trata de una región de la ontología que aún no ha sido tematizada suficientemente, si bien G. Marcel encara perfectamente el problema.

Así, pues, G. Marcel es, en mi opinión, un gran ontólogo. Uno de los grandes ontólogos de nuestro siglo. Marcel aún no está bien estudiado, quien más y quien menos ha encontrado una excelente idea suelta al leer sus obras, pero la estructura interna de las rutas seguidas hasta llegar a esos resultados, aún no ha sido abordada. El problema es el de encontrar un método adecuado.

Pero, vamos a ver qué tipo de ontología hace el autor de El Misterio del Ser: «Se me preguntará si esta intersubjetividad que coloco a la base de la Ontología puede dar lugar a alguna proposición simple y directamente formulable. :...Si no es una afirmación enunciable, ¿no será sólo un deseo que erroneamente se toma por una comprobación? ..Pero esta palabra "comprobación» debe de retener nuestra atención por algunos instantes. ¿Qué puedo comprobar? Un hecho, nada más que un hecho, y un hecho es algo que se me da. Pero por definición es evidente que lo que llamaré nexo intersubjetivo no puede dárseme, puesto que de alguna manera estoy implicado en él. Quizá no

42. F. EBNER, Das Wort und die geistigen Realitaten. Innsbruck, 1921.

43. K. LOWITH, Das Individuum in der Rolle des Mitmenschen. Munich, 1928.

44. P. Lain Entralgo, Teorfa y Realidad del otro. Madrid, 1961. 
sea inexacto decir que ese nexo es en realidad la condición necesaria para que algo me sea dado ${ }^{45}$.

Cuando nos movemos en el terreno del misterio, la dificultad para explorar es mayor, ya que el lenguaje de lo misterioso es distinto del lenguaje y contexto de lo problemático. Es una dificultad comparable con la que se produciría si tuviéramos que formular juicios condenatorios imparciales sobre una persona muy querida. La categoría de juicio está en distinta escala que la categoría amor, fidelidad creadora, etc. En el segundo caso estamos en el terreno de lo inverificable: «Es evidente que el nexo intersubjetivo de ninguna manera puede comprobarse; sólo puede reconocerse. ...iQué buscamos exactamente? No es un hecho, ni tampoco una forma en el sentido tradicional del término; sin duda más valdría hablar de una estructura, a condición de recordar que cuando se habla de estructura habitualmente se evoca algo que se presenta como un objeto susceptible de considerarse desde afuera. Ahora bien, aquí se trata, si puede decirse, del interior de la estructura, y de un interior del que debemos reconocer que, en nuestra condición de seres finitos y un tanto ligados al habitat terrestre, no nos es dado hacer corresponder un exterior $"{ }^{46}$.

Para Marcel la verdad está en las cosas y no en el juicio. Intenta descubrir la verdad de las cosas, o mejor, de las personas y de sus relaciones, que las constituyen. Las personas existén más eminentemente que los otros entes porque son los únicos seres capaces de desvelar la verdad del ser y sus relaciones (nos referimos a los seres-que-están-en-el-mundo).

«La intersubjetividad a la que hemos accedido no sin esfuerzo, debe ser en realidad, como el terreno sobre el que vamos a establecernos para continuar nuestras investigaciones... Pero una toma de posición semejante, de inmediato pone de manifiesto el carácter anticartesiano de la metafísica hacia la cual vamos a tener que orientarnos. No basta decir que es una metafísica del ser: es una metafísica del somos, por oposición a la metafísica del yo pienso" ${ }^{47}$.

Si bien la intersubjetividad y el ser no se identifican, si tenemos que afirmar que son frutos del mismo territorio y que están interrelacionados: «¿Puede decirse que, en suma, hemos llegado a identificar ser y subjetividad? ¿Diremos que el ser es la intersubjetividad?

De inmediato diré que no creo posible suscribir esta posición tomada literalmente. La verdad me parece aquí mucho más sutil, y exige enunciarse en un lenguaje a la vez más riguroso y más matizado.

45. G. MARCEL, Le Mystère de l'Être. trad. Castellana de M.E. Valentié, Buenos Aires, 1964,187 .

46. G. MARCEL, Le Mystère de l'Etre. trad. Castellana de M.E. Valentié, Buenos Aires, 1964, 188-189.

47. G. MARCEL, Le Mystere de l'Etre. trad. Castellana de M.E. Valentié, Buenos Aires, 1964, 186-187. 
Lo que creo percibir - y en este dominio sin duda es preferible expresarse en un tono dubitativo - es que el pensamiento que se dirige al ser restaura al mismo tiempo a su alrededor esa presencia intersubjetiva que una filosofia de inspiración nonádica comienza por exorcizar de la manera más arbitraria» ${ }^{48}$.

Entramos en la esfera del tener (avoir) cuando el ego protagoniza gnoseológicamente la verdad, si la verdad estuviera sólo en el juicio, y todo pudiera ser objetivable y categorizable. El nosotros relacional nos sumerge en el ser, en lo inverificable (no en lo irracional): «Se podría decir, quizás, en un lenguaje más inmediatamente captable, que el espesor del ser se adelgaza en la medida en que el ego pretende atribuirse una posicición central en la economía del conocimiento. Inversamente, cuanto más reconoce el ego que es uno entre otros, con una infinidad de otros con los que mantiene relaciones a menudo indescifrables, más tiende a recobrar el sentido de esta espesura.

Seamos cautos, sin embargo: si nos limitamos a decir que el ego es simplemente uno entre otros, lo atomizamos inevitablemente, lo reducimos a la condición de un elemento numerable. Ahora bien, si insistí tanto en la intersubjetividad, es justamente para poner el acento sobre la presencia de una profundidad sentida, de una comunidad profundamente arraigada en lo ontológico, sin la cual los lazos reales humanos serían ininteligibles o, más exactamente, deberían considerarse exclusivamente míticos» ${ }^{49}$.

Se trata de textos centrales para entender a G. Marcel, y su concepción dialógica. A pesar de la dificultad que uno encuentra al caminar entre estos textos, hay que reconocerle a G. Marcel el esfuerzo en clarificar la cuestión mediante «aproximaciones sucesivas». «En un lenguaje más concreto, digamos: no me preocupo por el ser, sino en la medida en que tomo conciencia más o menos indistinta de la unidad subyacente que me une a otros seres cuya realidad presiento. Estos seres son ... my fellow-creatures» ${ }^{50}$.

Estamos situados en una región óntica donde la libertad humana adquiere el máximo protagonismo. Estamos más en el reino de la voluntad que en el reino de la crítica. El consentimiento al ser no puede imponerse, por tanto podemos desconocer el ser o negarlo.

No se trata, sin embargo, de un camino irracional, sino del reino de la libertad creadora. «El ser es» resulta una proposición dicha por mi libertad y a otros seres libres. El reino del misterio no es irracional, pero tampoco objetivable, es reconocible o a reconocer. La ontología tiene atmósfera misteriosa,

48. G. MARCEL, Le Mystère de l'Étre. trad. Castellana de M.E. Valentié, Buenos Aires, 1964, 191-192.

49. G. MARCEL, Le Mystère de l'Être. trad. Castellana de M.E. Valentié, Buenos Aires, $1964,192$.

50. G. MARCEL, Le Mystère de l'Être. trad. Castellana de M.E. Valentié, Buenos Aires, 1964, 192-193. 
no problemática, y el misterio nos pone en contacto con el ser, «aceptar el misterio ontológico es consentimiento al ser" ${ }^{51}$.

Se puede hablar de una coincidencia de lo misterioso y de lo óntico, en donde lo inverificable - pero libremente consentido- se impone sobre lo categorizable: «L'expression mystère de l'être, mystère ontologique par opposition à problème de l'être, à problème ontologique m'est venue brusquement ces jours-ci. Elle m'a illuminé... Coincidence du mystérieux et de l'ontologique» ${ }^{52}$.

Un problema se puede resolver con datos suficientes, pero un misterio no se puede reducir a datos: "L'être comme principe d'inexhaustibilité. ...Le propre des problèmes est de se détailler. Le mystère est au contraire ce qui ne se détaille pas»" ${ }^{53}$.

Es necesario destacar la importancia del término o sentido de la presencia —presencia misteriosa - por oposición a no-presencia o ausencia: «La verdad es que el objeto está ligado a un conjunto de técnicas ensenables. Justamente ocurre lo contrario cuando se trata de la presencia»" ${ }^{54}$.

No toda relación con el otro es dialógica, misteriosa, puede ser también problemática o destructiva. Puede darse presencia física y no darse presencia misteriosa, verdadera presencia. Yo puedo estar con alguien en una habitación, y sin embargo sentirme muy distante de él. También puede suceder lo contrario: una persona querida que se encuentra lejos puede tornarse presente en un determinado momento. Cuando se establece una relación creativa o dialógica con una persona se da la presencia: «...Puede ocurrir que el otro cuando lo siento presente me renueve, en cierto modo, interiormente; esta presencia es entonces reveladora, es decir, me hace ser plenamente lo que yo no sería sin ella» ${ }^{55}$.

G. Marcel resume así el contenido de la presencia: «Pero desde ahora veamos que todos los desarrollos anteriores desembocan en una interpretación que la presentan como misterio y no como un simple hecho objetivo" ${ }^{36}$.

Deberíamos dedicar algunas páginas a la corporeidad — presencia de mi propio cuerpo-, pero dado el carácter de este trabajo, nos limitaremos, por ahora, a esbozar el tema: «Yo soy un ser a quien su ser mismo se aparece co-

51. M.F. SciaCA, La filosofia oggi. Trad. castellana de C. Matons y J.J. Ruiz. 3 vols. Barrelona, 1956, 398.

52. G. MARCEL, Journal Métaphysique (Etre et avoir). Paris, 1968, 124-125.

53. G. MARCEL, Journal Métaphysique (Être et avoir). Paris, 1968, 126-127.

54. G. MARCEL, Le Mystère de l'Étre. trad. Castellana de M.E. Valentié, Buenos Aires, $1964,167$.

55. G. MARCEL, Le Mystère de l'Être. trad. Castellana de M.E. Valentié, Buenos Aires, $1964,167$.

56. G. MARCEL, Le Mystère de l'Etre. trad. Castellana de M.E. Valentié, Buenos Aires, $1964,171$. 
mo misterio" ${ }^{57}$. La cuestión de la somatización puede sugerirnos que: «Le problème des rapports de l'âme et du corps est plus qu'un problème» ${ }^{58}$.

Cuando me relaciono con las personas, tomo contacto con las cosas, mi cuerpo está como interpuesto, como mediador entre ellas y yo: «Ahora bien, si me adhiero a la presentación puramente instrumentalista de lo que yo denomino mi cuerpo, tropezaré con obstáculos más serios aún. Observemos en primer lugar que la expresión "yo me sirvo de mi cuerpo» deja subsistir un margen harto extenso entre ella y la experiencia confusa y rica que ella pretende traducir. En la conciencia que yo tengo de mi cuerpo, de mis relaciones con mi cuerpo, hay algo que esa relación no indica; de ahí esta protesta casi imposible de reprimir: "yo no me sirvo de mi cuerpo, yo soy mi cuerpo»" 39.

Sería interesante calibrar el estilo de la ontología marcealiana, compararla, incluso con la de Heidegger, Hartmann o Scheler. G. Marcel nos habla de sus afinidades con Heidegger. Procuraremos ejemplificar esta cercanía intelectual, de una manera especial al tratar del sentido de la creatividad, de la relación creadora.

Max Scheler ${ }^{60}$ pertenece a la familia de los pensadores dialógicos, y, al parecer, desempeño un papel notable: «...Ya en este siglo, Max Scheler dio un empellón, sin demasiadas consideraciones, al navío encallado, y la corriente espiritualista y personalista -Ebner, Haecker, Marcel, Lavelle, Le Senne, etc., se instaló de lleno en los estratos superiores del ser» ${ }^{61}$.

La cita anterior relaciona el pensamiento dialógico con la Filosofía del Espíritu y Personalista, pero, ¿qué relación guarda M. Heidegger con este movimiento? "Il me semble qu'il y aurait entre Heidegger et moi quelque chose comme un accorde liminaire quant à la necesité, en assurant si l'on peut dire ontologiquemente les valeurs, de les hausser à un niveau où elles devienent plus que des valeurs, ceci s'appliquant autant au bien qu'à la vérité»" ${ }^{62}$.

Al tiempo que G. Marcel nos recuerda su vecindad ontológica con Heidegger, intenta deshacer entuertos sobre la clasificación que pretende encasillar a los filósofos existenciales en «existencialistas cristianos y existencialistas ateos»: "Chacun sait ou devrait savoir aujourd'hui que cette classification ne tient pas. En admettant même que Heidegger puisse être appelé un

57: G. MARCEL, Journal Métaphysique. trad. Castellana de J. Rovira. Buenos Aires, 1957, 287.

58. G. MARCEL, Journal Métaphysique (Être et avoir). Paris, 1968, 138.

59. G. MARCEL, Objectivité et Existence. Publicada como apéndice a Journal Métaphysique. trad. Castellana de J. Rovira. Buenos Aires, 1957, 322.

60. M. Scheler, Die Stellung des Menschen im Kosmos. Trad. Castellana de J. Gaos. Buenos Aires, 1971.

61. A. LOPEZ QUINTÁs, Metodología de lo suprasensible. Madrid, 1963, 19-20.

62. G. MARCEL, Testament philosophique. Revue de Métaphysique et de Morale, $n .^{\circ} 3$ (1969), 258. 
existencialiste, ce qui est fort douteux, il a rejeté catégoriquement la dénomination d'athée. J'ajouterai qu'en fait, lui et moi, nous sommes infiniment plus proches l'un de l'autre qu'il ne l'est de Sartre ou que je ne le suis de Jarpers» ${ }^{63}$.

$\mathrm{Si}$, «la claridad es la cortesía del filosofo», uno no siempre es todo lo "cortés» que desearía. Incluso se podría decir que la cortesía la regatearon los dioses a los aprendices de filósofos. Por eso, intentaremos, de nuevo, hacer un poco más transparente las grandes líneas del pensamiento dialógico; pondremos algunos ejemplos.

Pensemos, dice, G. Marcel, en un ejemplo sencillo y concreto, intentado descubrir la transformación interior que se puede producir en el seno de una relación personal. Pensemos en un marido que comenzó por considerar a su mujer como un objeto relativo a sí mismo, a los goces que le podía proporcionar o a los servicios que le podría prestar. Si un día este marido logra descubrir que esa mujer tiene una realidad y un valor propios, si comienza a tratarla como igual, a reconocerla como otra persona, como existente en sí, llegará a poder sacrificar caprichos, etc., que antes tenían una importancia condicionada, y sus relaciones serán de otro estilo. «Estamos ante un cambio de experiencia que ilustra directamente mi pensamiento. Este cambio afecta al centro; digamos más bien que el pensamiento sustituye un centro por otro; $y$ desde luego la palabra pensamiento no es muy exacta, puesto que se trata de la actitud misma del ser considerada en su totalidad, y en tanto toma cuerpo en sus actos" ${ }^{64}$.

El pensamiento dialógico es un nuevo estilo de ser y de pensar la relación humana ${ }^{65}$. Marcel habla con insistencia de su teatro por que en él hay ejemplos vivientes de esta relación dialógica. El teatro es la quintaesencia de su filosofía vertida en situaciones concretas y relativamente transparentes: «Si ahora, después de estas largas y difíciles explicaciones, me vuelvo hacia la cuestión, formulada al principio de esta conferencia, acerca de la relación entre mi persona y mi obra, sin que pueda esperar resolverla completamente, creo que por lo menos puedo decir lo siguiente: si tengo derecho a hablar de una presencia de mí mismo en mi obra, es únicamente en la medida en que este yo ha encontrado progresivamente una unidad entre los distintos aspectos que al principio habían estado disociados. Pero es evidente que esta unidad debe de ser comprendida dinámicamente... Cuanto más se considere esta unidad, más se verá que reside en la unión de una actividad creadora, por una parte, y

63. G. MARCEL, Testament philosophique. Revue de Métaphysique et de Morale, $\mathrm{n} .^{\circ} 3$ (1969), 254-255. 1964,50 .

64. G: MARCEL, Le Mystère de l'Etre. trad. Castellana de M.E. Valentié, Buenos Aires,

65. A. LOPEZ QuinTÁs, Conferencia pronunciada en el Congreso de Filosofía de Alcalá de Henares. Julio, 1979. 
por otra, de una filosofía de esta actividad creadora. Pero al expresarme así, creo que os ayudo a que comprendáis mejor lo que vengo diciendo desde hace diez años, que en el conjunto de mis obras, el teatro ocupa el primer lugar y no la filosofía» ${ }^{66}$.

Pondremos también un ejemplo tomado de Heidegger. Al leer a $\mathrm{M}$. Heidegger, uno tiene la impresión de que está releyendo a Hegel. Parece que quiere aclarar algo que Hegel no especificó bien. «Pero entonces, ¿es la obra todavía obra cuando está fuera de la relación? ¿No pertenece a la obra, precisamente, esto de estar en relaciones? En todo caso sólo resta preguntar en cuáles relaciones está.

¿Adónde pertenece una obra? La obra, como tal, únicamente pertenece al reino que se abre por medio de ella. Pues el ser obra de la obra existe y sólo en esa apertura» ${ }^{67}$.

M. Heidegger parece que completó aspectos de la filosofía marceliana de la creatividad. Es un artesano de la creatividad estética. Junto con Hegel profundiza el acto creativo y el resultado del camino creador. La verdad de la creatividad nutre las páginas que Hegel y Heidegger dedican a la Estética.

G. Marcel elaboró preferentemente una ontología de las relaciones humanas, pero sólo dejó iniciada su reflexión sobre la obra de arte y el cometido de las cosas en relación con los seres-que-están-en-el-mundo. Heidegger comprendió que la verdad no es solamente una relación personal verdadera, sino que la verdad está también en las cosas: "Llamamos verdadera no sólo a una proposición, sino también a una cosa, por ejemplo oro verdadero" ${ }^{68}$.

La ontología marceliana discurre, en algunos momentos, paralela a la de Heidegger. Algunas opiniones heideggerianas sobre la creatividad podrían ser suscritas por Marcel. «Ser obra significa establecer un mundo. Pero ¿qué es eso de un mundo! ...Mundo es lo siempre inobjetivable y del que dependemos, mientras los caminos del nacimiento y de la muerte, la bendición y la maldición nos retienen absortos en el ser. ...La piedra no tiene mundo, las plantas y los animales tampoco lo tienen; pero sí pertenecen al impulso oculto de un ambiente en que están sumergidos... En cambio la campesina tiene un mundo porque se mantiene en lo abierto de lo existente» ${ }^{69}$.

Pueden crear solamente los seres capaces de comprender la verdad, y sólo los seres abiertos a la apertura del otro pueden ex-sistir en el mundo: «Lo que

66. G. MARCEL, Auf der Suche nach Wahrheit und Gerechtigkeit. Trad. castellana de J. Godo. Barcelona, 1973, 21-22.

67. M. HeIdegger, Der Ursprung des Kunstwerkes, Hölderlin und das Wesen der Dichtung. Trad. castellana de S. Ramos. México, 1973, 70.

68. M. Heidegger, Der Ursprung des Kunstwerkes, Holderlin und das Wesen der Dichtung. Trad. castellana de S. Ramos. México, 1973, 82.

69. M. Heidegger, Der Ursprung des Kunstwerkes, Holderlin und das Wesen der Dichtung. Trad. castellana de S. Ramos. México, 1973, 74-75. 
se dice «ser» es abierto en la comprensión del ser que es inherente como comprender al «ser ahí» existente» ${ }^{70}$.

Abordamos, pues, el ejemplo del templo griego. Un templo, nos dice Heidegger, no es solamente un edificio de piedra unida de acuerdo con unos sistemas de fuerzas que lo mantienen en pie. Es también parte del templo, el cimiento rocoso que lo sostiene y cuyas entrañas resisten el empuje de la piedra que brilla bajo el sol. Un templo es el trabajo reunido de muchos obreros, es para un fin, es relativo a un dios, capacidad de congregar, «unidad de vías y relaciones».

Un templo no es solamente el templo construido, sino también el templo para..., para ser visto, interpretado, inundado por la mirada o el sentimiento de los fieles «que tienen mundo».

El pensamiento dialógico procura reunir, actualizar todas las relaciones de una obra o persona para que confluyan en un punto o en un momento y sean para el hombre, que en ese momento, como en un electrizamiento total, se reúne en el templo o lo consagra: «El establecimiento es, como tal, la erección en el sentido de la consagración y de la gloria. El establecimiento ya no significa aquí la mera colocación. Consagrar significa santificar en el sentido de que en la construcción que es obra (Wekhaft), lo sagrado se abre como sagrado y el dios es llamado a lo patente de su presencia»" ${ }^{71}$.

La presencia es una forma especial de ser en relación con otro. «Mediante el templo está en él presente el dios. Esta presencia del dios es en sí la ampliación y delimitación del recinto como sagrado. Pero el templo y su recinto no se esfuman en lo indeterminado. El templo por primera vez construye y congrega simultáneamente en torno suyo la unidad de aquellas vías y relaciones en las cuales el nacimiento y la muerte, la desdicha y la felicidad, la victoria y la ignominia, la perseverancia y la ruina, toman la forma y el curso del destino del ser humano. La poderosa amplitud de estas relacionees patentes es el mundo de este pueblo histórico. Partiendo de tal ámbito, dentro de él se vuelve un pueblo sobre sí mismo para cumplir su destino» ${ }^{72}$.

Otro gran pensador alemán, M. Buber, descubrió, paralelamente a Marcel las posibilidades del pensamiento dialógico. También entendió que la relación era, en realidad, polivalente: «Le monde de la relation s'établit dans trois sphères:

La première est celle de la vie avec la Nature...

70. M. Heidegger, Sein und Zeit. Trad. castellana de J. Gaos. México, $1974{ }^{5}, 470$.

71. M. HeIDEgGer, Der Ursprung des Kunstwerkes, Holderlin und das Wesen der Dichtung. Trad. castellana de S. Ramos. México, 1973, 73-74.

12. M. HeIDEgGer, Der Ursprung des Kunstwerkes, Holderlin und das Wesen der Dichtung. Trad. castellana de S. Ramos. México, 1973, 71. 
La deuxième es la vie avec les hommes. La relation y est manifeste et explicite. Nous pouvons y donner et y recevoir le $\mathrm{Tu}$.

La troisieme est la communion avec les essences spirituelles» ${ }^{73}$.

El libro de M. Buber, Ich und $D u$, adquirió gran difusión y puede contribuir notablemente al conocimiento del pensamiento dialógico. Pero, el lector suele poetizar este libro, perdiendo así las grandes posibilidades filosóficas, que tiene. Lo dialógico no es - o por lo menos, no es sólo- poesía y profecía, es fundamentalmente ontología.

A partir de Rosenstork (1924), el pensamiento dialógico encuentra eco en temáticas como el diálogo, el misterio, etc. También en H.U. von Balthasar, A. Brunner, K. Rahner, M.D. Chenu, J. Mouroux, O. Semmelroth, H. de Lubac, J. Daniélou, D. Congar, y otros.

El movimiento dialógico se extiende también a la literatura. H. Hesse sería un buen ejemplo. El lobo estepario habla del rico potencial que podrían comunicar algunas personas, aisladas por diversas circunstancias. Se trata de un lamento de incomunicación que nos despierta a buscar nuevas formas y más auténticas de comunicarse. Los lobos son buscadores, pueden caminar solos toda una noche, pero necesitan reunirse con otros. H. Hesse -escritor dialógico - cita expresamente a pensadores dialógicos para expresarles su simpatía: «...Una edición completa de Goethe y otra de Jean Paul eran al parecer muy usadas, lo mismo Novalis y también Lessing, Jacobi y Lichtenberg. Algunos tomos de Dostoievski estaban llenos de papeles cuajados de notas» ${ }^{74}$.

La relación dialógica empapa también el existir y la poesía de Miguel Hernández. Todos sus versos son intersubjetividad dialógica, desde los primeros que escribió un pastor, a los últimos que grabó en la pared de su celda de la cárcel:

«Adiós, hermanos, camaradas y amigos

despedidme del sol y de los trigos».

Se pueden reseñar algunos momentos de mayor transparencia dialógica, la Canción del esposo soldado, la Elegía a Ramón Sijé («con quien tanto quería»):

«A las aladas almas de las rosas

del almendro de nata te requiero

que tenemos que hablar de muchas cosas,

compañero del alma, compañero».

73. M. Buber, Ich und Du. Trad. francesa de G. Bianquis. Paris, 1969, 23. (Avant-Propos de G. Marcel, Préface de G. Bachelard).

74. H. HesSE, Der Steppenwolf. Trad. castellana de M. Manzanares. Madrid, $1978{ }^{13}, 16$. 
Si hacemos un análisis del poema Aceituneros, veremos que existen concentraciones de momentos y relaciones, ya descritos en Heidegger:

«....No los levantó la nada,

ni el dinero, ni el señor,

sino la tierra callada,

el trabajo y el sudor.

Unidos al agua pura

y a los planetas unidos,

los tres dieron la hermosura

de los troncos retorcidos".

Los olivos son, pues, como la conjunción en un momento del empuje de la tierra, del trabajo, del agua y de los planetas.

Los versos anteriores condensan la estructura de la Fenomenología del Espíritu, de forma análoga, por supuesto. Primero aparece la relación amoesclavo, con reconocimiento unilateral y desigual. Esta relación no puede engendrar intersubjetividad, imposibilitando la fecundidad dialógica:

los levantó la nada,

ni el dinero, ni el señor».

Pero existe una alternativa a esta situación estéril. Esta alternativa sólo puede ser el reconocimiento mutuo, en igualdad, llevado a cabo por los trabajadores sin amo.

La presencia dialógica, pues, palpita en todos aquellos artistas, obreros, intelectuales que promueven relaciones creativas de igualdad, «concentrando la totalidad del ser y del destino humano»-como diría Marcel-, «Porque las estirpes condenadas a cien años de soledad no tenían una segunda oportunidad sobre la tierra» ${ }^{75}$.

Madrid, septiembre de 1979.

Antonio Natal Álvarez

75. G. García MÁrQuez, Cien afios de soledad. Barcelona, 1979, 334. 